DOI:10.2478/rrlm-2020-0010

\title{
HBV genotypes circulation in pregnant women in Romania: a pilot study
}

\author{
Odette Popovici ${ }^{1}$, Ramona Gabriela Ursu ${ }^{2 *}$, Doina Azoicai ${ }^{3}$, \\ Luminita Smaranda Iancu ${ }^{4}$
}

\author{
1. National Institute of Public Health Romania - National Centre for \\ Communicable Diseases Surveillance and Control \\ 2. University of Medicine and Pharmacy "Grigore T. Popa" Iași, Microbiology Discipline \\ 3. University of Medicine and Pharmacy "Grigore T. Popa" Iași, Epidemiology Discipline \\ 4. University of Medicine and Pharmacy "Grigore T. Popa" Iași, Microbiology Discipline, National \\ Institute of Public Health-Regional Center of Public Health Iași
}

\begin{abstract}
Background: The risk of mother to child transmission of hepatitis B virus (HBV) is recognized worldwide, a reason for which the World Health Organization aims to reduce this public health issue of major concern in the next ten years. The aim of our study was to detect circulating HBV genotypes in a selected population of pregnant women, as scientific evidence to recommend personalized antiviral therapy and to obtain updated epidemiological information. Methods: HBsAg positive pregnant women were selected by the National Institute of Public Health Romania. Blood samples were collected after signing the informed consent. The HBV genotypes were tested by INNO LiPA HBV genotyping method. Results. The D genotype was detected in 9/18 (50\%) patients, genotype A in 3/18 (16.7\%), and genotype F in 3/18 (16.7\%) patients. Three patients had double infection, 11 had unique infection, and 4 had no detectable genotype. Conclusion. This study confirmed the results of previous studies regarding $H B V$ genotype circulation in our country, with the mention that F genotype was a new one for our area. These data are useful from an epidemiological point of view and also for therapeutical reasons, as it is known that therapy should be genotype guided.
\end{abstract}

Keywors: $H B V$, genotype, pregnant women, antiviral therapy

Received: 11 th October 2019; Accepted: $12^{\text {nd }}$ January 2020; Published: $17^{\text {th }}$ January 2020

*Corresponding author: Ramona Gabriela Ursu, University of Medicine and Pharmacy "Grigore T. Popa” Iași, Romania. E-mail: ramonagabrielaursu@yahoo.com, ramona.ursu@umfiasi.ro 


\section{Background}

The World Health Organisation (WHO) recognizes the risk of maternal transmisson of HBV to newborns, therefore the plan is to reduce this risk by the end of 2030 (1). The International Agency for Research on Cancer (IARC) lists HBV as one of the known biological agents involved in human carcinogenesis since 1993 (2). Two hundred and forty million people are known worldwide with chronic HBV infection, with variation between 2 and $8 \%$, acording to each regional endemicity levels. In some countries, HBsAg prevalence is decreasing due to vaccination and probably due to efficient therapy. An actual problem is the migration of population which leads to prevalence changes in countries with known low endemicity (e.g., Italy, Germany) (3).

The estimated age-standardized incidence rate in 2018, for liver cancer, both genders, all ages for Romania was 8.4, value which is one of the highest in Europe (4). A special category of HBV infected patients are the pregnant women, regarding the risk of transmission to new borns. Recently, the seroprevalence of HBV infection markers in this patients category has been evaluated in Romania, and a 5.1\% prevalence of HBsAg was detected and a $7.4 \%$ for HBeAg among the HBsAg positive ones (5). The proportion of childbearing age women having natural immunity after HBV infection varied between 6.9 and $19.2 \%$ and increased with age group (6).

Viral markers such as HBeAg and HBV-DNA are known to influence the risk of hepatocellular carcinoma (HCC). Also, the viral genotype seems to modify the risk of HCC, but this data are difficult to analyze because of the global variation in viral genotypes circulation (2). Ten genotypes of HBV have been identified and labeled A to J. In comparison with genotypes $\mathrm{B}$ and $\mathrm{D}$, genotype $\mathrm{A}$ is associated with significantly higher rates of $\mathrm{HBeAg}$ and $\mathrm{HBsAg}$ loss as a result of interferon (IFN) therapy. Differences have beed observed regarding the natural history of genotpes $\mathrm{B}$ and $\mathrm{C}$ evolution to $\mathrm{HCC}$, in different areas of the world (e.g., Asia, Alaska) (7).

The starting point for our research was the previous studies performed on pregnant women in Romania, aiming to estimate the seroprevalence of HBV markers of infection (5) and also studies which evaluated the HBV genotypes in patients with chronic HBV infection $(8,9)$. As HBV perinatal transmission is a problem of major concern, we thought that it is important to provide scientific evidence for personalized antiviral therapy and for public health interventions.

The aim of this pilot study was to evaluate the HBV genotype circulation in a selected group pregnant women, from different regions of Romania, in order to establish personalized therapy and to obtain updated epidemiological information.

\section{Material and methods}

The selection of HBsAg positive pregnant women was done by the National Institute of Public Health Romania - National Centre for Communicable Diseases Surveillance and Control. The pregnant women were selected as the first who gave their consent to participate in the study. The number of subjects was imposed by the available financial resources. Of all the pregnant women who were tested for HBV markers during routine pregnancy control between May and August 2018, eighteen HBsAg positive pregnant women were selected from 4 different counties of Romania (Iași, Călărași, Sibiu, and Suceava). Sixteen out of 18 pregnant women presented themselves for HBsAg testing at the general practitioner, and only 2 were tested in maternity, immediately after admission to give birth. Blood samples were then sent to the Virology Laboratory of „Grigore T. Popa" University of Medicine and Pharmacy, Iași. The same protocol for HBV genotype detection was used for all samples. 


\section{Research ethics}

All the patients included in this study signed the informed consent approved by the Research Ethics Committee of „Grigore T. Popa” University of Medicine and Pharmacy Iași. The study follows the international recommendations on human studies as stated by the Declaration of Helsinki.

The INNO LiPA HBV genotyping method followed the next steps: DNA purification, PCR amplification (outer and nested amplification), hybridisation of the amplicons, detection of HBV genotypes by strip hybridisation. All these steps were described in details previously $(8,9)$.

\section{Results}

The median age of pregnant women was 31 years (23-39), and the median age of pregnancy was 28 weeks (9-39). Demographic and labo- ratory data can be seen in Table I. None of the pregnant women had been vaccinated and none was in antiviral treatment. Three patients had double infection, 11 had unique infection, and 4 had no detectable genotype. The $\mathrm{D}$ genotype was detected in $9 / 18(50 \%)$ patients, genotype $\mathrm{A}$ in $3 / 18(16.7 \%)$, and genotype $\mathrm{F}$ in $3 / 18(16.7 \%)$ patients.

\section{Discussion}

In this study we confirmed our previous findings in patients with chronic HBV infections, using the same HBV genotyping method: D is the most frequent HBV genotype in our area, followed by A genotype, as unique or in double infections $(8,9)$.

Many other authors have published their results regarding HBV genotype circulation worldwide, mentioning also the natural history of HBV infection and the role of HBV genotypes.

Table I. Demographic data, age of pregnancy, quantity of purified DNA, purity and the $\mathrm{HBV}$ detected genotypes

\begin{tabular}{ccccccc}
\hline $\begin{array}{c}\text { Crt. } \\
\text { number }\end{array}$ & County & $\begin{array}{c}\text { Age of pregnant } \\
\text { woman (years) }\end{array}$ & $\begin{array}{c}\text { Age of pregnancy } \\
\text { (weeks) }\end{array}$ & $\begin{array}{c}\text { DNA quantity } \\
\text { ng/ } \boldsymbol{\mu l}\end{array}$ & $\begin{array}{c}\text { DNA purity } \\
\text { A 260/280 }\end{array}$ & $\begin{array}{c}\text { HBV } \\
\text { genotype }\end{array}$ \\
\hline 1 & Iasi & 30 & 36 & 33,4 & 2.000 & $\mathrm{D}, \mathrm{F}$ \\
\hline 2 & Iasi & 32 & 35 & 42,9 & 1,955 & $\mathrm{D}, \mathrm{F}$ \\
\hline 3 & Iasi & 37 & 39 & 89,3 & 1,904 & $\mathrm{~A}, \mathrm{~F}$ \\
\hline 4 & Iasi & 34 & 16 & 54,4 & 1,946 & $\mathrm{D}$ \\
\hline 5 & Iasi & 23 & 32 & 76,3 & 1,866 & $\mathrm{D}$ \\
\hline 6 & Iasi & 23 & 13 & 31,9 & 1,939 & $\mathrm{D}$ \\
\hline 7 & Iasi & 35 & 16 & 25,9 & 1,857 & $\mathrm{D}$ \\
\hline 8 & Iasi & 32 & 15 & 90,3 & 1,885 & $\mathrm{D}$ \\
\hline 9 & Iasi & 28 & 36 & 57,4 & 1,885 & $\mathrm{D}$ \\
\hline 10 & Iasi & 29 & 37 & 28,9 & 1,933 & $\mathrm{D}$ \\
\hline 11 & Iasi & 31 & 32 & 20,5 & 2,05 & $\mathrm{D}$ \\
\hline 12 & Iasi & 30 & 9 & 17 & 2,1 & $\mathrm{~A}$ \\
\hline 13 & Iasi & 31 & 39 & 11,0 & 2,000 & $*$ \\
\hline 14 & Iasi & 23 & 31 & 13,0 & 2,167 & $*$ \\
\hline 15 & Calarasi & 27 & 24 & 19,5 & 2,167 & $\mathrm{~A}$ \\
\hline 16 & Calarasi & 39 & 22 & 24 & 2,087 & $*$ \\
\hline 17 & Suceava & 32 & 18 & 29,4 & 2,107 & $*$ \\
\hline 18 & Sibiu & 28 & 18 & 64,4 & 1,738 & $\mathrm{D}$ \\
\hline$*$ undetectable & & & & &
\end{tabular}

* undetectable 
A research team from Fundeni Clinical Institute, Bucharest, detected the same two genotypes D and $\mathrm{A}$ in Romanian chronic infected patients (10, 11). In a recent review, Kmet Lunaček et al. confirmed the A and D genotype distribution in Europe, but also mentioned that $41 \%$ of non-A-D genotypes were identified in some European countries (12). Thereby, we mention the study of Toy $\mathrm{M}$ et al. in which the Dutch chronic B hepatitis (CHB) patients were detected positive for genotypes $\mathrm{B}, \mathrm{C}$, and $\mathrm{G}$ besides the known $\mathrm{A}$ and D genotypes (13). Also, in a study conducted on French population, Moussa $\mathrm{S}$ et al. detected genotype D, followed by E (14). Ghany MG et al. identified the distribution of HBV genotypes in a North American cohort (A 18\%, B 39\%, C $33 \%$, D $8 \%$, E 3\%, and other $1 \%$ ) and correlated the genotype with Asian, White, and Black races. Interestingly, among Whites they found genotypes A (55\%) and D (33\%) and this distribution was also correlated with the place of birth - Europe (15). A recent review highlights the relations between HBV genotypes and mutants, and hepatitis B vaccine failure, acute and chronic HBV infection, HBeAg seroconversion and HBsAg seroclearance, with the purpose to implement individualized management for HBV infected patients (16).

Some papers mention the subtypes of HBV and their role in influencing the response to antiviral therapy $(17,18)$, a relevant reason to test chronic infected patients. In a comprehensive review, Pourkarim MR et al. showed the role of the almost forty subgenotypes of $\mathrm{HBV}$ in the natural history of HBV infection. Also, the authors suggested the introduction of the term "immigro-subgenotype" to distinguish exotic (sub) genotypes from local known genotypes in each area of the world. The hope of the authors is that by vaccination, accurate diagnosis method, and monitoring therapy, elimination of HBV could be achieved (17). In another review of Rajoriya $\mathrm{N}$ et al., the genotype of HBV was mentioned as the first viral factor involved in a personalised medicine approach for the future treatment of hepatitis B infection (18).

Compared with the previous regional studies carried out in Romania, this study is also mostly a regional one, as $78 \%$ of tested pregnant women were from the North-East region, and only a few patients belonged to other counties (Calarași, Sibiu, and Suceava). Detection of F genotype of HBV in 3 cases, in double infection with A and D genotypes, was an unexpected result given the known global geographical distribution of HBV genotypes. We reviewed the literature and we found in a recent review that $\mathrm{F}$ genotype of HBV is usually present in South and in Central America, but it was also detected at the Arctic Circle and in Spain (19). Another recent review (Velkov S et al., 2018) established the following genotype distribution within chronic HBV infections: $0.86 \%$ for $\mathrm{F}$ genotype, $22.1 \%$ for $\mathrm{D}$, and $16.9 \%$, for A genotype. The authors of this paper analyzed the genotyping results of 26,319 HBV-infected individuals from 125 countries. $75 \%$ of studies analyzed the HBV genotype by sequencing and the rest by PCR - based methods. These authors also mentioned that genotypes F - I together account for only $1.3 \%$ of all infections, mostly in Latin America (20). There are not many studies published about $\mathrm{F}$ genotype, but we can mention that it was detected the second as prevalence in different regions of Brasil (21). Regarding its role in pathogenesis, Marciano S et al. specify that genotype $\mathrm{F}$ is correlated with a higher risk of HCC and mortality, and the respose to interferon is similar with that of genotype A (22). As a support for our findings is the study of Hirzel $\mathrm{C}$ et al. which detected genotype $\mathrm{F}$ in 5 cases $(1.1 \%)$ in a retrospective cohort study on Swiss patients having different countries of birth, using the same genotyping method (e.g., INNO LiPA) (23).

This study highlights for the first time the F genotype circulation in Romania, which is why these 
3 cases have been thoroughly investigated from an epidemiological point of view. No direct or indirect $\operatorname{link}(\mathrm{s})$ with the above-mentioned geographical regions/country have been established. One of them could have been exposed, through a transfusion, 20 years before, and another one mentioned a long stay of her husband for work, in another European country.

The risk of mother-to-child transmission of HBV is correlated with an elevated risk of developing $\mathrm{CHB}$, cirrhosis and $\mathrm{HCC}$, and therefore, many professional associations have developed guidelines for the diagnosis and monitoring of pregnant women in order to reduce this transmission. One of them is the 2018 Guide of American Association for the Study of Liver Diseases (AASLD) which recommends the counseling of pregnant women for HBV vaccination, breast feeding, monitoring of HBsAg positive women, the risk of mother to child transmission, the necessity of testing the sexual partners for HBV. The same guideline suggest that HBsAg positive pregnant women should be tested for liver transaminases, HBV - DNA and assessed for the utility of antiviral therapy (7). The EASL (European Association for the Study of the Liver) 2017 Clinical Practice Guidelines suggest that in pregnant women with high HBV- DNA viral load or high levels of HBsAg, antiviral therapy should be initiated (3). The guidelines recognize the utility of HBV genotyping, as different responses to peg-IFN therapy were seen for different genotypes of HBV. Perinatal transmission from $\mathrm{HBsAg}$ positive pregnant women with high level of HBV-DNA could be reduced by antiviral therapy (7).

HBV genotyping in pregnant women was also performed by other authors. In a similar study to ours, $21 \mathrm{HBsAg}$ positive out of 1489 Japanese pregnant women were detected positive for genotype $\mathrm{C}$ in 14 cases, D in six cases, and undetermined in one case (24). In a Chinese pregnant women study group, genotypes $\mathrm{B}$ and $\mathrm{C}$ of $\mathrm{HBV}$ were detected, genotype $\mathrm{C}$ being considered a risk factor for mother to child transmission (25). Denmark is another country which introduced HBV genotyping for pregnant women, genotype $\mathrm{C}$ being the most prevalent in their population (26). The pregnant women from an antenatal clinic in UK were detected positive for genotypes E (13/40, 32.5\%) and B (10/40, 25\%) as predominant, and for genotypes A $(6 / 40,15 \%)$, $\mathrm{C}(9 / 40,22.5 \%)$, and $\mathrm{D}(2 / 40,5 \%)$ in lower proportion (27). In a study performed in France, the author did not find any relation between the HBV genotype or origin of the patients and the risk of mother to child tranmission (28).

We are confident in our HBV genotyping method, as it is an optimized assay which has amplification, conjugation positive and negative controls. Four patients known to be HBsAg positive had no HBV genotype detectable. We analysed the literature and we found at least two other articles which reported the same untypable HBV genotypes. Possible explanations could be some immune escape mutants or the lower sensitivity of our genotyping method, so the untypable genotype can be completely identified only by sequencing and phylogenetic analysis of the S gene $(29,30)$ which was not the case in this study. A recent study from Norway supports this information, as the authors mentioned that their molecular epidemiology analysis indicated a geographical clustering of sequences depending on their geographical origin (31). Still, a comparison was performed between the Sanger sequencing assay and INNO Lipa method and the authors found a very good correlation of the results of both assays (32).

Another application of INNO LiPA is to test antiviral resistance. A multidisciplinary team concluded in a clinical trial that TDF (tenofovir) alone is safe and effective for the treatment of patients with lamivudine-resistant, chronic HBV infection (33).

From our point of view, the major disadvantage of INNO LiPA assay is that it is time consuming 
(14 hours all procedure), and secondly, the costs which cannot be supported by patients. More developed techniques have beed used by other authors for HBV genotyping: Real Time PCR or sequencing $(32,34)$. The future of HBV testing regarding the genotypes worldwide distribution and antiviral resistance is by far the sequencing analysis, which, in countries such as Romania, requires larger studies. Due to financial constraints, this study was limited to only 18 pregnant women.

To achieve the elimination goal (1), building on such pilot studies that bring valuable data on circulating genotypes, personalized therapy, combined with public health actions at national level, could be keys to success.

\section{Conclusions}

In this study, we detected the genotypes of HBV in a group of pregnant women. The most frequent genotype was $\mathrm{D}$, followed by $\mathrm{A}$ and $\mathrm{F}$. The last one has never been described in our country to date. These data are important from an epidemiological point of view, regarding the HBV genotype circulation, and also for guiding a personalized antiviral therapy in case of chronic hepatitis B.
Abbreviations
AASLD - American Association for the Study of Liver Diseases
CHB - chronic B hepatitis
EASL - European Association for the Study of the Liver
HBV - hepatitis B virus
HCC - hepatocellular carcinoma
IARC - International Agency for Research on
Cancer
IFN - interferon
WHO - World Health Organisation

\section{Acknowledgments}

We would like to thank the colleagues in the 4 participating county public health authorities (CPHA), with a special mention for Dr. Elena Duca, epidemiologist in Iasi CPHA.

\section{Authors' contributions}

O.P. coordinated the study, contributed to the methodology, collected the data, undertook the data analysis and participated in drafting the manuscript.

R.G.U. contributed to the methodology, performed the genotyping procedure, participated in drafting the manuscript.

D.A. and L.S.I. were involved in revising the article critically for important intellectual content; and final approval of the version to be published.

\section{Conflict of interest}

None to declare.

\section{References}

1. WHO Regional Committee for Europe, Action plan for the health sector response to viral hepatitis in the WHO European Region, WHO Regional Office for Europe, UN City, Marmorvej 51, DK-2100 Copenhagen Ø, Denmark, 2017, viii +44 pages.

2. IARC Working Group, HEPATITIS B VIRUS, International Agency for Research on Cancer, IARC Working Group on the Evaluation of Carcinogenic Risks to Humans. 150 cours Albert Thomas, 69372 Lyon Cedex 08, France, 2012;100(Pt B):1-441.

3. Lampertico P, Agarwal K, Berg T, Buti M, Janssen HLA, Papatheodoridis G, et al. EASL 2017 Clinical Practice Guidelines on the management of hepatitis B virus infection. J Hepatol. 2017 Aug;67(2):370-98. DOI: 10.1016/j.jhep.2017.03.021

4. Bray F, Ferlay J, Soerjomataram I, Siegel RL, Torre LA, Jemal A. Global cancer statistics 2018: GLOBOCAN estimates of incidence and mortality worldwide for 36 cancers in 185 countries. CA Cancer J Clin. 2018 Nov;68(6):394-424. DOI: 10.3322/caac.21492

5. Popovici O, Radu R, Romaniuc A, Azoicăi D. A seroprevalence study for hepatitis $B$ virus markers of infection in pregnant women in Romania: results and oppor- 
tunities for prevention. J Gastrointestin Liver Dis. 2018 Jun;27(2):133-7. DOI: 10.15403/jgld.2014.1121.272. $\mathrm{hpb}$

6. Popovici O, Molnar GB, Popovici F, Janţă D, Pistol A, Azoicăi D. A Seroprevalence Study of Hepatitis B and C Virus Infections in a Hospitalized Population in Romania, an Opportunity for a Better National Prevention and Control Strategy. J Gastrointestin Liver Dis. 2016 Mar;25(1):25-32. DOI: 10.15403/jgld.2014.1121.251. $\mathrm{hbc}$

7. Terrault NA, Lok ASF, McMahon BJ, Chang KM, Hwang JP, Jonas MM, et al. Update on Prevention, Diagnosis, and Treatment of Chronic Hepatitis B: AASLD 2018 Hepatitis B Guidance. Clin Liver Dis (Hoboken). 2018 Aug 22;12(1):33-4. DOI: 10.1002/cld.728

8. Ursu RG, Luca CM, Luca AS, Toader E, Simion L, Iancu LS. Laboratory diagnosis for optimize therapy of B hepatitis virus infection by using biochemical and molecular biology methods. Rev. Chim. (Bucharest), 2016; 67(12): 2614-261.

9. Luca AS, Luca MC, Ursu RG, Iancu LS. The Study of VHB genotypes in a population - a pilot study. Rev. Chim. (Bucharest), 2016; 67(3): 500-2.

10. Constantinescu I, Nedelcu F, Toader MA, Daniela V. Clinical and therapeutical importance of HBV genotyping in Romania. J Med Life. 2008 Apr-Jun;1(2):165-73.

11. Constantinescu I, Dinu AA, Boscaiu V, Niculescu M. Hepatitis B virus core promoter mutations in patients with chronic hepatitis B and hepatocellular carcinoma in bucharest, Romania. Hepat Mon. 2014 Oct 20;14(10):e22072. DOI: 10.5812/hepatmon.22072

12. Kmet Lunaček N, Poljak M, Matičič M. Distribution of hepatitis B virus genotypes in Europe and clinical implications: a review. Acta Dermatovenerol Alp Pannonica Adriat. 2018 Sep;27(3):141-6. DOI: 10.15570/ actaapa. 2018.28

13. Toy M, Veldhuijzen IK, Mostert MC, de Man RA, Richardus JH. Transmission routes of hepatitis B virus infection in chronic hepatitis B patients in The Netherlands. J Med Virol. 2008 Mar;80(3):399-404. DOI: 10.1002/jmv.21098

14. Moussa S, Brah S, Parola P, Gerolami R, Gamerre M, Boubli L, et al. Epidemiological, clinical, virological features of hepatitis B newly diagnosed in 2011 in Marseille University hospitals, southeastern France. J Med Virol. 2016 May;88(5):828-36. DOI: 10.1002/ jmv. 24398

15. Ghany MG, Perrillo R, Li R, Belle SH, Janssen HL, Terrault NA et al. Characteristics of adults in the hepatitis B research network in North America reflect their country of origin and hepatitis B virus genotype. Clin Gastroenterol Hepatol. 2015 Jan;13(1):183-92.

16. Lin CL, Kao JH. Natural history of acute and chronic hepatitis B: The role of HBV genotypes and mutants. Best Pract Res Clin Gastroenterol. 2017 Jun;31(3):249-
55. DOI: 10.1016/j.bpg.2017.04.010

17. Pourkarim MR, Amini-Bavil-Olyaee S, Kurbanov F, Van Ranst M, Tacke F. Molecular identification of hepatitis B virus genotypes/subgenotypes: revised classification hurdles and updated resolutions. World J Gastroenterol. 2014 Jun 21;20(23):7152-68. DOI: 10.3748/ wjg.v20.i23.7152

18. Rajoriya N, Combet C, Zoulim F, Janssen HLA. How viral genetic variants and genotypes influence disease and treatment outcome of chronic hepatitis B. Time for an individualised approach? J Hepatol. 2017 Dec;67(6):1281-97. DOI: 10.1016/j.jhep.2017.07.011

19. Sunbul M. Hepatitis B virus genotypes: global distribution and clinical importance. World J Gastroenterol. 2014 May 14;20(18):5427-34. DOI: 10.3748/wjg.v20. i18.5427

20. Velkov S, Ott JJ, Protzer U, Michler T. The Global Hepatitis B Virus Genotype Distribution Approximated from Available Genotyping Data. Genes (Basel). 2018 Oct 15;9(10). DOI: 10.3390/genes9100495

21. Lampe E, Mello FCA, do Espírito-Santo MP, Oliveira CMC, Bertolini DA, Gonçales NSL, et al. Nationwide overview of the distribution of hepatitis $\mathrm{B}$ virus genotypes in Brazil: a 1000-sample multicentre study. J Gen Virol. 2017 Jun;98(6):1389-98. DOI: 10.1099/ jgv.0.000789

22. Marciano S, Galdame OA, Gadano AC. HBV genotype F: natural history and treatment. Antivir Ther. 2013;18(3 Pt B):485-8. DOI: 10.3851/IMP2604

23. Hirzel C, Wandeler G, Owczarek M, Gorgievski-Hrisoho M, Dufour JF, Semmo N, et al. Molecular epidemiology of hepatitis B virus infection in Switzerland: a retrospective cohort study. BMC Infect Dis. 2015 Oct 30;15:483. DOI: 10.1186/s12879-015-1234-z

24. Michitaka K, Hiraoka A, Imai Y, Utsunomiya H, Tatsukawa H, Shimizu Y, et al. Clinical features and hepatitis $B$ virus (HBV) genotypes in pregnant women chronically infected with HBV. Intern Med. 2012;51(24):331722. DOI: $10.2169 /$ internalmedicine.51.8596

25. Ding Y, Sheng Q, Ma L, Dou X. Chronic HBV infection among pregnant women and their infants in Shenyang, China. Virol J. 2013 Jan 7;10:17. DOI: 10.1186/1743422X-10-17

26. Harder KM, Cowan S, Eriksen MB, Krarup HB, Christensen PB. Universal screening for hepatitis B among pregnant women led to $96 \%$ vaccination coverage among newborns of HBsAg positive mothers in Denmark. Vaccine. 2011 Nov 21;29(50):9303-7. DOI: 10.1016/j.vaccine.2011.10.028

27. Dervisevic S, Ijaz S, Chaudry S, Tedder RS. Non-A hepatitis B virus genotypes in antenatal clinics, United Kingdom. Emerg Infect Dis. 2007 Nov;13(11):168993. DOI: $10.3201 /$ eid1311.070578

28. Sellier P, Maylin S, Amarsy R, Mazeron MC, Larrouy L, Haïm-Boukobza S, et al. Untreated highly viraemic 
pregnant women from Asia or sub-Saharan Africa often transmit hepatitis B virus despite serovaccination to newborns. Liver Int. 2015 Feb;35(2):409-16. DOI: 10.1111/liv.12561

29. Faleye TO, Adewumi MO, Ifeorah IM, Omoruyi EC, Bakarey SA, Akere A, et al. Detection of hepatitis B virus isolates with mutations associated with immune escape mutants among pregnant women in Ibadan, southwestern Nigeria. Springerplus. 2015 Feb 1;4:43. DOI: 10.1186/s40064-015-0813-1

30. Baclig MO, Reyes KG, Liles VR, Gopez-Cervantes J. Untypable genotype restriction patterns and surface gene variants of hepatitis B virus isolates. Int J Mol Epidemiol Genet. 2017 Jun 20;8(3):19-26.

31. Pettersson JH, Myking S, Elshaug H, Bygdås KIE, Stene-Johansen K. Molecular epidemiology of hepatitis B virus infection in Norway. BMC Infect Dis. 2019 Mar 7;19(1):236. DOI: 10.1186/s12879-019-3868-8
32. Alidjinou EK, Bocket L, Pigot V, Lambert V, Hallaert $\mathrm{C}$, Canva V, et al. Sanger sequencing versus INNO-LiPA ${ }^{\circledR}$ HBV PreCore assay for routine detection of precore and basal core promoter mutations in hepatitis virus $\mathrm{B}$ chronically infected patients. Diagn Microbiol Infect Dis. 2018 Apr;90(4):277-279. DOI: 10.1016/j.diagmicrobio.2017.12.006

33. Fung S, Kwan P, Fabri M, Horban A, Pelemis M, Hann HW et al. Randomized comparison of tenofovir disoproxil fumarate vs emtricitabine and tenofovir disoproxil fumarate in patients with lamivudine-resistant chronic hepatitis B. Gastroenterology. 2014 Apr;146(4):980-8. DOI: 10.1053/j.gastro.2013.12.028

34. Chevaliez S, Dauvillier C, Dubernet F, Poveda JD, Laperche S, Hézode C, et al. The New Aptima HBV Quant Real-Time TMA Assay Accurately Quantifies Hepatitis B Virus DNA from Genotypes A to F. J Clin Microbiol. 2017 Apr;55(4):1211-9. DOI: 10.1128/JCM.02219-16 